\title{
ASSOCIATION OF PARTICULATE MATTER (PM) WITH RESPIRATORY SYMPTOMS AMONG CHILDREN IN SELECTED PRIMARY SCHOOLS IN PAHANG
}

\author{
Maryam, Z. ${ }^{1}$, Hazrin, A. H. ${ }^{1}$, Hizrri, A. ${ }^{1}$, Norhidayah, A. ${ }^{2}$, Samsuddin, N.. ${ }^{3}$ Mohd Shukri, M.A. ${ }^{*}$ \\ ${ }^{1}$ Department of Biotechnology, Kulliyyah of Science, International Islamic University Malaysia, Kuantan Campus, Pahang \\ ${ }^{2}$ Department of Occupational Safety and Health, Faculty of Technology, University Malaysia Pahang, Gambang Campus, Pahang \\ ${ }^{3}$ Department of Biomedical Sciences, Kulliyyah of Allied Health Sciences, International Islamic University Malaysia, Kuantan Campus, Pahang \\ *Corresponding author email: mamshukri@iium.edu.my
}

\section{ARTICLE DETAILS}

\section{Article History:}

Received 12 November 2017 Accepted 12 December 2017 Available online 1 January 2018

\section{Keywords:}

particulate matter (PM), respiratory symptoms, IAQ, schools, children

\section{ABSTRACT}

Particulate matter (PM) is one of the primary pollutants found in the indoor environment. It can cause deterioration of the indoor air quality (IAQ) and is often linked with adverse health effects especially towards susceptible subgroup of the population like children. School children are exposed to PM inside the classroom, as this indoor PM may originate from both indoor and outdoor sources. Furthermore, ambient surrounding could be one of the major factors that contribute to its high concentration, specifically for school environment like government-subsidized schools in Malaysia whereby the schools are using natural ventilation systems to control the thermal comfort inside the classrooms. Hence the infiltration of outdoor PM into the indoor is probably high and significant. The high concentration of PM may affect the children's health and learning performances. Due to this reason, it is important to study the effects of PM towards children. Thus, this study aims to assess the concentrations of PM and selected IAQ parameters in the school indoor environment with distinct background characteristics including residential, industrial, and rural areas. PM and IAQ parameters (temperature, relative humidity (RH), carbon monoxide (CO) and carbon dioxide $\left(\mathrm{CO}_{2}\right)$ ) were assessed for 8-hours duration via DustMate Environmental Dust Detector (Turnkey Instruments, USA) and VelociCalc ${ }^{\circledR}$ Multi-Function Ventilation Meter 9565 (TSI ${ }^{\circledR}$, USA) respectively, during occupied and non-occupied time in the classrooms. Second, considering the children's prolonged and repetitive exposure towards PM in school indoor environment and their body sensitivity, this study also screened for the prevalence of non-specific respiratory disease (NSRD) and persistent cough and phlegm (PCP) among children via structured questionnaire developed by American Thoracic Society's Division of Lung Diseases (ATS-DLD-78-C). Higher concentrations of PM and prevalence of respiratory symptoms in the school from the industrial area were expected, due to the high concentration of PM originated from nearby industrial activities and anthropogenic sources. Hopefully, better understanding and insights on the issue were obtained through this study.

\section{INTRODUCTION}

Poor IAQ in school might have detrimental effects on the children in their learning ability and academic performance but also later effects when they grow up as well as may affect their life in the future and subsequently to the society [1]. Other than an indoor area like home, they spend most of their times in school. Therefore, IAQ in school is a growing concern nowadays as students spend about 5 to 7 hours in the school.

School children deserve good IAQ because the children have greater susceptibility to some environmental pollutants than adults. Their immune and respiratory system are still immature body mass index of children is inferior and their breathing pattern is making them more susceptible to the air pollutants [2]. Air pollutants like PM can be originated from outdoor and indoor of the buildings.

There are several outdoor and indoor activities that influenced the concentrations of air pollutants thus affect IAQ inside the school especially the classroom. Nearby busy traffic road, manufacturing factories and corrosion of building materials are the factors that may influence the IAQ inside the classrooms [3]. Higher density of occupants inside the classroom and student's activities are also influenced IAQ in the classroom [4].

To provide the optimum IAQ for the students, government and parents must play their role to give the best to the future leader. These children depend upon an adult to help them grow strong and healthy through good IAQ. It was reported that indoor air pollutants may exacerbate diseases like asthma and allergy. These diseases lead to absenteeism which later might impair learning and performance in school [5]. As the impact of the
IAQ is so alarming, the data and further study needed to at least create awareness about the importance of good IAQ among parents and government.

Therefore, the primary objective of this study is to determine the concentration air pollutants such as PM and other IAQ parameters inside the classrooms with different background locations (residential, industrial, and rural areas). Secondly, this study aims to screen for the prevalence of NSRD and PCP by using structured questionnaire ATS-DLD78-C.

\section{METHODOLOGY}

\subsection{Site description}

Three selected government primary schools around Pahang were monitored for a total of four days for both during the non-occupied and occupied time. Each school represented contrasting background known as residential, industrial, and rural areas. The chosen primary schools were SK Indera Mahkota (SKIM), Indera Mahkota, Kuantan (349'07.2"N $\left.103^{\circ} 17^{\prime} 53.0^{\prime \prime E}\right)$, SK Balok Baru (SKBB), Balok, Kuantan (357'37.6"N $\left.103^{\circ} 22^{\prime} 52.3^{\prime \prime E}\right)$, and SK Teh (SKT), Batu Embun, Jerantut (3⒌'07.6"N $102^{\circ} 21^{\prime} 03.2^{\prime \prime E}$ ). Within the classroom, only one point of sampling has been chosen considering the total volume of the selected classrooms were < $3000 \mathrm{~m}^{3}$ and the total floor area $<500 \mathrm{~m}^{2}$. Besides, minimal interferences to the class activities also considered.

In general, government primary schools were designed with natural ventilation systems utilising mechanical ceiling fans and open windows for the control of its thermal comfort. The classrooms were equipped with 
furniture made up of press woods including table, chair, and cabinet. Whiteboard and marker pens were used as the teaching materials replacing the conventional blackboard and chalks. For SKBB and SKT, the school operated in a single session (morning only) while SKIM operated in two sessions (morning and afternoon). Classrooms occupancy were within the range of 28-36 persons.

\subsection{Data collection}

\subsubsection{IAQ Assessment}

The sampling was based on 8-hour time-weighted average (TWA). PM and IAQ parameters including temperature, relative humidity, and gaseous pollutants $\left(\mathrm{CO}\right.$ and $\mathrm{CO}_{2}$ ) were assessed for 8-hours duration via DustMate Environmental Dust Detector (Turnkey Instruments, USA) and VelociCalc $^{\circledR}$ Multi-Function Ventilation Meter 9565 (TSI ${ }^{\circledR}$, Minnesota, USA). $\mathrm{CO}$ and $\mathrm{CO}_{2}$ were measured by using non-dispersive infrared (NDIR) analyser (Model: IAQ Probe 982) while temperature and RH were measured by using hot-wire probe (Model: Thermo-anemometer Straight Probe 964). Every sampling days started from the beginning of school period. The point for sampling has been placed at the back of the classroom, with all the instruments positioned at the height of sitting school children's breathing zone ( \pm 0.75 meters above the floor) and about 1 meter away from the walls and windows.

\subsubsection{Questionnaire Administration}

Respiratory health status of children was assessed by using a wellvalidated questionnaire developed by American Thoracic Society questionnaire (ATS-DLD-78-C) with slight modification to suit the target population. The symptoms of respiratory diseases were divided into the non-specific respiratory disease (NSRD) and persistent cough and phlegm (PCP). Analysis of the questionnaire was based on the operational definition adopted from a study [6]. Criteria for NSRD are (i) chronic bronchitis: phlegm production from the chest $\geq$ two times/day for $\geq$ four days/week for $\geq$ three months/year for at least three years; (ii) bronchial asthma: doctor-diagnosed asthma and still have asthma; (iii) dyspnoea and wheezing: wheezing or whistling in the chest apart from cold on most days or nights. Criteria for PCP are (i) persistent cough: a cough apart from cold on most days more than four days/week for three months/year for at least one year; and (ii) persistent phlegm: congested in the chest or bring up phlegm, sputum, or mucus apart from cold on most days more than four days/week for three months/year for at least one year. The target population were approached via convenience sampling to ensure the data collected were representative. The parent-assisted method of questionnaire completion was applied among the participants. The sample size was estimated based on the previous prevalence of respiratory symptoms conducted by a group researcher [5].

\subsection{Data analysis}

The IAQ parameters measured were compared with Industry Code of Practice (ICOP) on Indoor Air Quality 2010 established by DOSH. Descriptive and inferential statistical tests were performed by using IBM SPSS Statistics version 22.0 and Microsoft Excel 2016. Descriptive statistics were used to describe IAQ parameters including PM, temperature, and RH. For questionnaire analysis, descriptive analysis was used to describe socio-demographic of children while differences and association between respiratory symptoms and PM were analysed by using chi-square test and correlations.

\section{RESULTS AND DISCUSSION}

\subsection{Particulate matter (PM)}

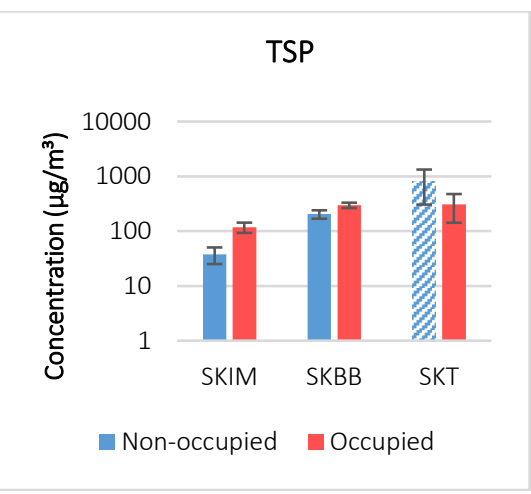

$1(\mathrm{a})$

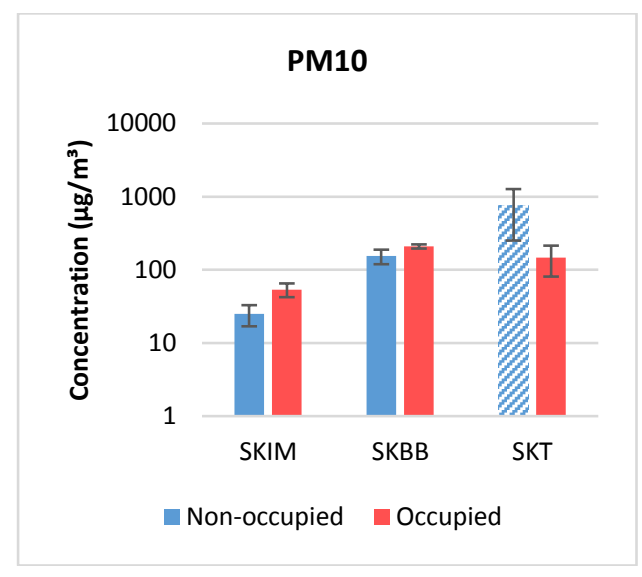

$1(\mathrm{~b})$

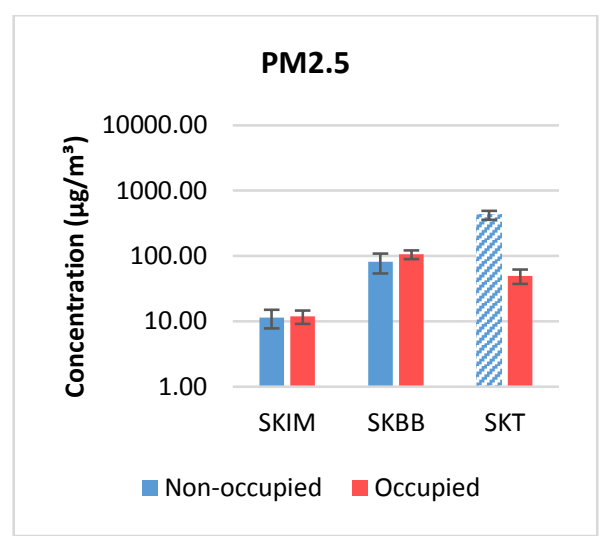

$1(\mathrm{c})$

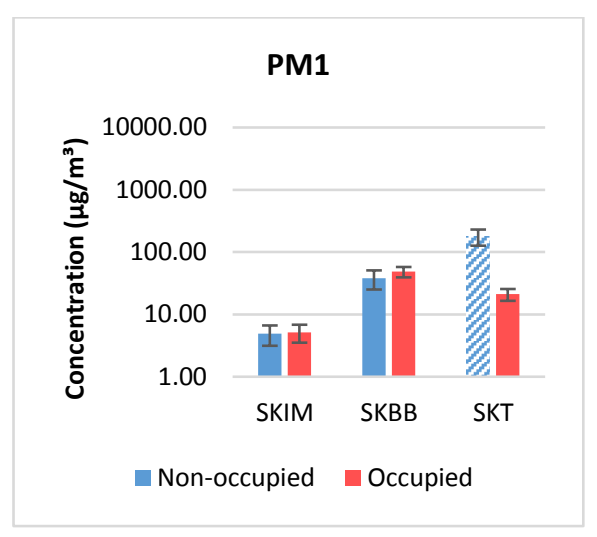

$1(d)$

Figure 1: 8-hour TWA of PM concentration

Figure 1 illustrates the 8-hour TWA of indoor PM concentrations along with the standard deviation at the selected primary schools. It should be first clarified that exclusion has been made on the data from SKT during the non-occupied period (as marked by the striped bar) as it was affected by haze episode. Thus, significantly higher concentrations of PM were observed in SKT during that time. Apart from that, the results obtained provide a clear trend in showing the industrial area possessed higher PM concentrations than rural and residential areas. Another noteworthy finding is the increased of PM concentrations during the presence of the children in the classroom, which has been observed in all classrooms.

On the other hand, it was found that during the normal and occupied time, the concentration of $\mathrm{PM}_{10}\left(>150 \mathrm{\mu g} / \mathrm{m}^{3}\right)$ in SKBB and $\mathrm{PM}_{2.5}\left(>35 \mathrm{\mu g} / \mathrm{m}^{3}\right)$ in SKBB and SKT were exceeding the standard limit of ICOP 2010 provided by DOSH, Malaysia and guidelines provided by the United States Environmental Protection Agency (U.S. EPA). This alarming situation should be avoided as school children deserve good IAQ inside their 
classroom. However, a high concentration of PM cannot be avoided due to many factors that influenced PM concentration. For example, high PM concentrations in the classrooms are mainly influenced by the factor of occupancy and ambient environment as reflected by the results in Figure 1. The presence of children in the classroom increased PM concentrations through various kind of mechanisms, primarily via the resuspension of deposited particles and delayed deposition caused by turbulence created by children's movements and activities [7,8]. From the observation, intense movements were seen while children entering the class from outdoor activities, recess time, sweeping activities, and end of each teaching sessions.

Apart from that, as a naturally ventilated building with open windows, infiltration of ambient particles also responsible for higher indoor concentrations. It is believed that higher indoor PM is possibly due to nearby industrial activities, traffic emissions, and other natural or anthropogenically sources located within the same vicinity with the school, being transported by the wind blowing mechanism [9]. Outdoor pollutants including vehicular and industrial emissions might worsen or enhance the underlying or pathophysiology of the respiratory system [10]. Hence, prolonged exposure towards diverse compositions and sizes could pose serious health hazard on children $[11,12]$.

Furthermore, the tendency of children to be particularly affected by the inhaled PM is higher than an adult. This is because their airways epithelium is more permeable to air pollutants and the lung defence are not fully evolved. Moreover, children also have a differential ability to metabolise, detoxify, and excrete environmental agents [13,14]. As the outdoor particles penetration seems to give substantial effects on the indoors, control of exposure should be implemented among the affected locations by redesigning the doors and windows to make it less penetrable for PM.

\subsection{Physical and chemical IAQ parameters}

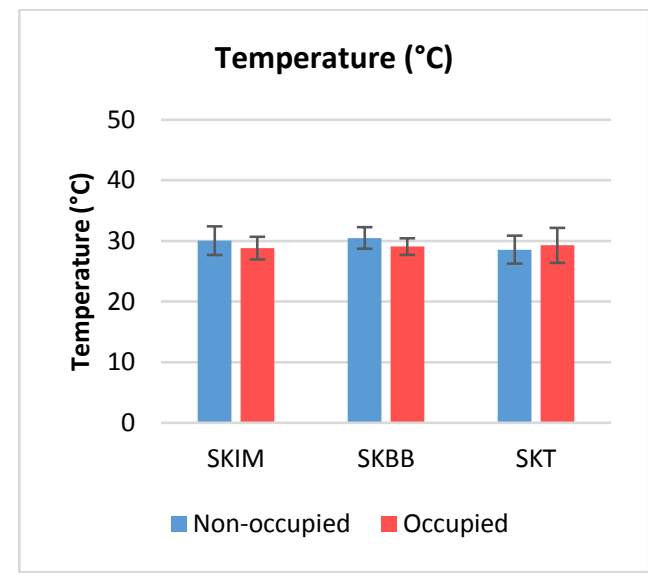

2(a)

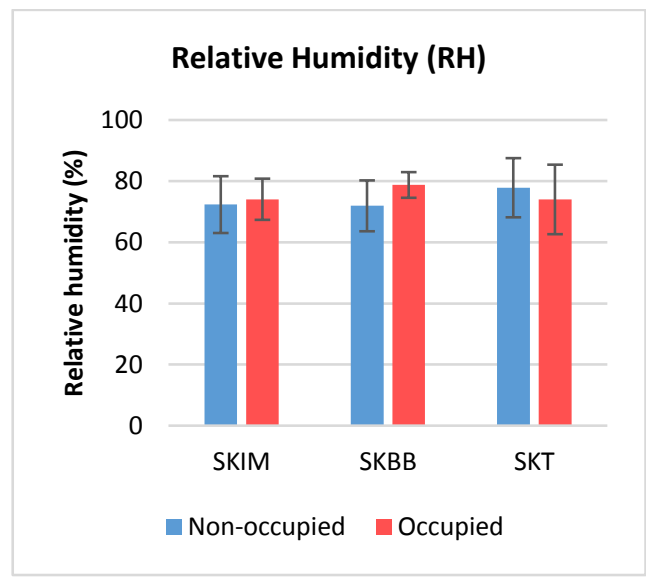

2(b)

Figure 2: IAQ physical parameters

The ICOP 2010 provides guidelines of the IAQ physical parameters in an indoor environment to ensure occupants' comfort and health. As recommended by the guidelines, the acceptable range for temperature is between $23-26{ }^{\circ} \mathrm{C}$ while $\mathrm{RH}$ is between $40-70 \%$. Surprisingly, none of these measured parameters was within the acceptable range (as in Figure 2). Perhaps this is likely due to the climate of this country. As a country located near the equator, Malaysia experiences hot and humid climate throughout the year. Referring to the result in Figure 2, the tropical climate conditions and natural ventilation system are believed to be the main factors in contributing to classrooms' high temperature and RH. Besides, these parameters were not much differed during the occupied and nonoccupied time, which reflects the major influenced of ambient climate instead of indoor-related factors. Instead of causing health problems directly, these unfavourable conditions are more related in causing discomfort, inconvenience, and distraction of children which possibly have an adverse effect on learning performance [1]. However, its effects may vary among individuals depending on their clothing, activity level, age, and physiological factors [12].

Apart from the issues of thermal comfort, temperature and RH also have been known to have effects on the indoor pollutants. Higher humidity tends to enhance particle growth via the transformation of finer particles to coarser size fractions [7] and boost the amplification of microbiological contaminants [12]. In contrast, recent evidence revealed that temperature has an inverse relationship with PM; in which high temperature in indoor environment will force the air out of the building hence diluting the indoor concentrations $[15,16]$.

It is worth noting that, gaseous pollutants including $\mathrm{CO}$ and $\mathrm{CO}_{2}$ were also being measured in this study. The results were not significant as the concentrations are much lower $\left(<2 \mathrm{ppm}\right.$ of $\mathrm{CO}$ and $<350 \mathrm{ppm}^{\circ} \mathrm{CO}_{2}$ ) than the ICOP 2010 guidelines ( $<10 \mathrm{ppm}$ for $\mathrm{CO}$ and $<1000 \mathrm{ppm}$ for $\mathrm{CO}_{2}$ ). This is mainly due to naturally ventilated classrooms which allowed air exchange through the open doors and windows. Air movement was generated by the ceiling fans somehow enhancing the air exchange with outdoor air. As there is no evidence of indoor CO emissions, the only possible sources are nearby vehicular emissions and industrial released. While for $\mathrm{CO}_{2}$ concentration, the concentration variability probably influenced by human occupancy.

\subsection{Questionnaire administration results}

\subsubsection{Socio-demographic and risk factors}

A total of 194 targeted school children participated in the study (9-11 years old). Only $81.4 \%$ of the returned questionnaires were completed by the subjects. The response rate was $82.3 \%$ in SKIM, 95.7\% in SKBB, and $65.1 \%$ in SKT respectively. In data analysis, incomplete or missing information was excluded.

In table 1, the percentages were calculated after excluding children who did not complete the required questions. As the children exposure towards airborne pollutants not solely happened in school, other environmental exposures and risk factors have also been taken into consideration. A study by a group of scientist reported that pupil with parental asthma had higher prevalence of cumulative incidents of respiratory problems including asthma $(p<0.05)$, wheeze $(p<0.001)$, and daytime attacks of breathlessness $(p<0.001)$ and pollen or pet allergy $(p<0.05)$ [17].

Table 1: Socio-demographic and risk factors among school children

\begin{tabular}{|c|c|c|c|c|}
\hline \multirow{2}{*}{ Parameter } & \multicolumn{3}{|c|}{$\mathrm{N}(\%)$} & \multirow{2}{*}{$\begin{array}{l}\text { Overall } \\
(\%)\end{array}$} \\
\hline & SKIM & SKBB & SKT & \\
\hline \multicolumn{5}{|l|}{ Gender } \\
\hline Male & $\begin{array}{c}24 \\
(48.0)\end{array}$ & $\begin{array}{c}25 \\
(39.1)\end{array}$ & 17 (41.5) & $66(42.6)$ \\
\hline Female & $\begin{array}{c}26 \\
(52.0)\end{array}$ & $\begin{array}{c}39 \\
(60.9)\end{array}$ & $24(58.5)$ & $89(57.5)$ \\
\hline \multicolumn{5}{|c|}{$\begin{array}{l}\text { Duration of time attending the } \\
\text { school }\end{array}$} \\
\hline$<6$ months & $2(3.9)$ & $3(4.5)$ & $0(0.0)$ & $5(3.2)$ \\
\hline$>6$ months & $\begin{array}{c}49 \\
(96.1)\end{array}$ & $\begin{array}{c}62 \\
(95.4)\end{array}$ & $\begin{array}{c}41 \\
(100.0)\end{array}$ & 152 (96.8) \\
\hline \multicolumn{5}{|c|}{$\begin{array}{c}\text { Smoking history among family } \\
\text { member }\end{array}$} \\
\hline Yes & $\begin{array}{c}25 \\
(49.0)\end{array}$ & $\begin{array}{c}37 \\
(56.9)\end{array}$ & $24(58.5)$ & $86(54.8)$ \\
\hline No & $\begin{array}{c}26 \\
(51.0)\end{array}$ & $\begin{array}{c}28 \\
(43.1)\end{array}$ & 17 (41.5) & $71(45.2)$ \\
\hline \multicolumn{5}{|l|}{ Pet } \\
\hline Yes & $\begin{array}{c}17 \\
(33.3)\end{array}$ & $\begin{array}{c}22 \\
(33.8)\end{array}$ & 17 (41.5) & $56(35.7)$ \\
\hline No & $\begin{array}{c}34 \\
(66.7)\end{array}$ & $\begin{array}{c}43 \\
(67.7)\end{array}$ & $24(58.5)$ & $101(64.3)$ \\
\hline
\end{tabular}




\section{Use of air conditioner/air}

humidifier

Yes

No

History of any lung-related disease

Yes

No

Family members

\begin{tabular}{lcccc}
$\leq 5$ & 25 & 30 & & $72(46.5)$ \\
& $(49.0)$ & $(47.6)$ & $17(41.5)$ & \\
$\geq 6$ & 26 & 33 & & $83(53.3)$ \\
\hline
\end{tabular}

*difference in total number of each criterion is due to exclusion of incomplete or missing data

In another study, family members significantly increased the prevalence of respiratory symptoms (OR=1.20, 95\% CI=1.05-1.37) and age slightly increased the significance of the risk of impaired lung functions $(O R=1.19$, 95\% CI= 1.07-1.34); however, its only restricted to the children whose mother completed their questionnaire [6]. Other researcher also found that exposure to passive smoking has raised the prevalence of respiratory symptoms among children and having furry pets were associated with rhinitis and wheeze [18]. These factors are worth noting for further statistical analysis. The data obtained from the questionnaires are summarised in Table 1.

\subsubsection{Respiratory symptoms}

Table 2: Prevalence of respiratory symptoms among school children

\begin{tabular}{ccccccc}
\hline & SKIM & SKBB & SKT & & & \\
Symptoms & $(\mathrm{n}=51)$ & $(\mathrm{n}=66)$ & $(\mathrm{n}=41)$ & $\begin{array}{c}X^{2} \\
(\%)\end{array}$ & $\begin{array}{c}\text { Pverall } \\
(\mathrm{df})\end{array}$ & $\begin{array}{c}\text { P. } \\
\text { value }\end{array}$ \\
& & & & & & \\
\hline
\end{tabular}

NSRD

Bronchial asthma

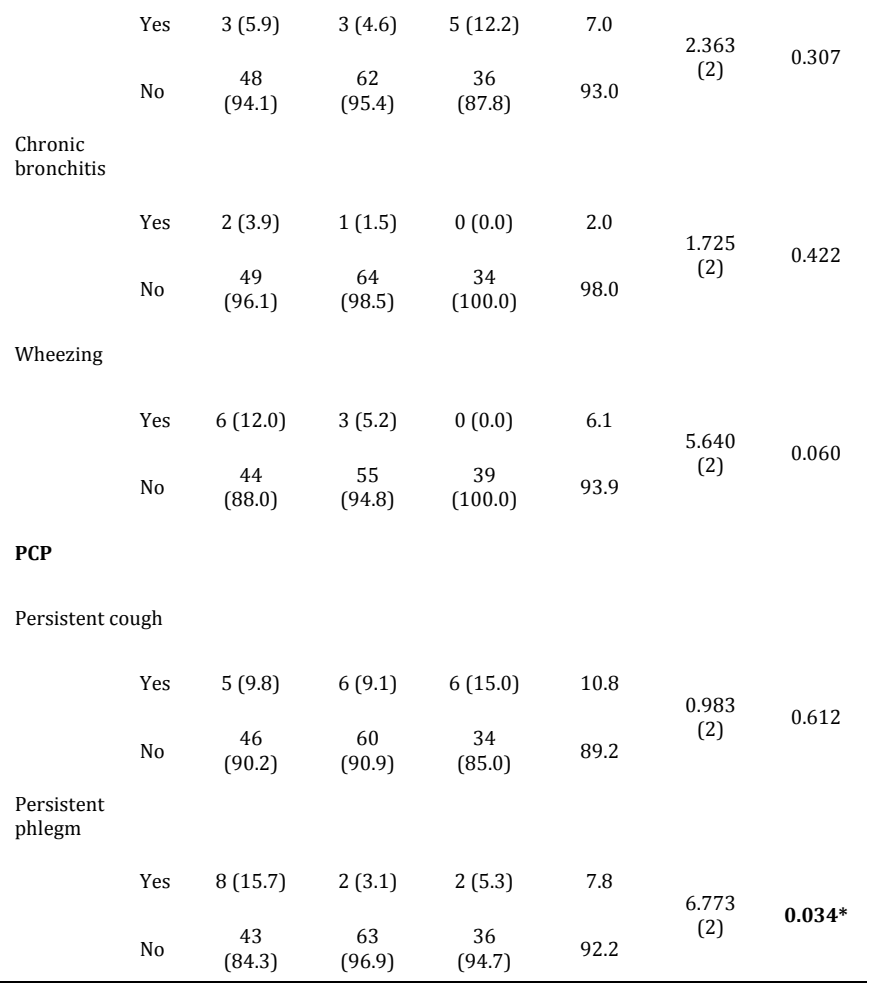

Table 2 shows the prevalence of NSRD and PCP of school children in the selected schools. In overall, symptoms that were most prevalent among the respondents were a persistent cough (10.8\%), persistent cough (7.8\%), bronchial asthma (7.0\%), wheezing (6.1\%), and chronic bronchitis (2.0\%). In details, persistent cough (15.0\%) and bronchial asthma (12.2\%) were most reported among children in SKT while chronic bronchitis $(3.9 \%)$, wheezing $(12.0 \%)$, and persistent phlegm $(15.7 \%)$ were most reported among children in SKIM. Chi-square test revealed that only persistent phlegm was significantly different between schools $\left(X^{2}=6.773\right.$ with $p$-value 0.034 at the degree of freedom of 2 ).

It was hypothesised that children attending a school located near industrial areas tend to experience more respiratory symptoms. Some local research found that the increase of outdoor airborne pollutants mainly due to nearby industrial activities often linked with the increase in the prevalence of respiratory symptoms. In an instance, a study by some researcher has demonstrated that school children living in an exposed area within the vicinity of the petrochemical industry of Kerteh, Terengganu have significantly higher respiratory symptoms compared to non-exposed area [5]. Similar research conducted among preschool children in Selangor, Malaysia by Rawi further support the fact of higher prevalence of respiratory symptoms were experienced among children who attended preschools in the area with heavy traffic density [19]. Contrary to expectations, results from this study did not in line with the previous research. We found that prevalence of respiratory symptoms among children in SKBB which located within the vicinity of industrial areas of Gebeng, Kuantan was lower compared to other areas.

Although highest PM concentrations were recorded in SKBB, its prevalence of respiratory symptoms among the children was relatively low compared to the others. It is believed that the symptoms are mainly due to confounding risk factors, including the level of home pollutants exposure, lifestyle, and history of health which probably have more substantial effects towards their health. Apart from that, PM is not necessarily the only factor in causing the respiratory symptoms. Other airborne pollutants which are not measured like NOx, TVOCs and formaldehyde might play a role in the development of the symptoms. This study lacks control on confounders. Besides, the respiratory symptoms have only been assessed via questionnaire, which might be biased due to variability in individual perception of the symptoms. However, the result of questionnaire analysis still reliable as the adapted material and methodology is well established.

\section{CONCLUSION}

This paper presented results of physical IAQ parameters like $\mathrm{PM}_{10}, \mathrm{PM}_{2.5}$ temperature and RH. Even though for $\mathrm{PM}_{10}$ concentration in SKBB and SKT, temperature and RH for all schools were exceeding the standard limit of ICOP 2010 provided by DOSH, Malaysia, these situations cannot be avoided due to several factors that influenced IAQ physical parameters like occupancy factor and the ambient environment.

This study also found that prevalence of respiratory symptoms among the children in SKBB was relatively low compared to the others even though high PM concentration was recorded in that area. The results of the present study also suggest that the respiratory symptoms are might be due to other confounding risk factors, including the level of home pollutants exposure, lifestyle, and history of health. These confounding factors probably have more significant effects towards the schoolchildren respiratory health.

\section{ACKNOWLEDGEMENT}

The authors would like to thank MOE for the funding through Fundamental Research Grant Scheme (FRGS14-113-0354) and their approval to conduct research at the chosen primary schools. The authors also would like to extend appreciation to IIUM and internal IIUM grants (RIGS16-316-0480), Pahang State Department of Education, and schools' authority for their kind cooperation.

\section{REFERENCES}

[1] Mendell, M. J., Heath, G. A. 2005. Do indoor pollutants and thermal conditions in schools' influence student performance? A critical review of the literature. Indoor Air, 15 (1), 27-52.

[2] Madureira, J., Paciência, I., Rufo, J., Ramos, E., Barros, H., Teixeira, J. P., de Oliveira Fernandes, E. 2015. Indoor air quality in schools and its relationship with children's respiratory symptoms. Atmospheric Environment, 118, 145-156.

[3] Wong, C.S.C., Li, X., Thornton, I. 2006. Urban environmental geochemistry of trace metals. Environmental Pollution, 142 (1), 1-16.

[4] Daisey, J. M., Angell, W. J., Apte, M. G. 2003. Indoor air quality, ventilation and health symptoms in schools: an analysis of existing information. Indoor Air, 13, 53-64.

[5] Ayuni, N. A., Juliana, J., Ibrahim, M. H. 2014. Exposure to $\mathrm{PM}_{10}$ and $\mathrm{NO}_{2}$ 
and Association with Respiratory Health among Primary School Children Living Near Petrochemical Industry Area at Kertih, Terengganu. Journal of Medical and Bioengineering, 3 (4), 282-287.

[6] Langkulsen, U., Jinsart, W., Karita, K., Yano, E. 2006. Respiratory symptoms and lung function in Bangkok school children. The European Journal of Public Health, 16 (6), 676-681.

[7] Chithra, V. S., Nagendra, S. S. 2012. Indoor air quality investigations in a naturally ventilated school building located close to an urban roadway in Chennai, India. Building and Environment, 54, 159-167.

[8] de Gennaro, G., Dambruoso, P. R., Loiotile, A. D., Di Gilio, A., Giungato, P., Tutino, M., Marzocca, A., Mazzone, A., Palmisani, J., Porcelli, F. 2014. Indoor air quality in schools. Environmental chemistry letters, 12 (4), 467482 .

[9] Triantafyllou, A. G., Kiros, E. S., Evagelopoulos, V. G. 2002. Respirable particulate matter at an urban and nearby industrial location: Concentrations and variability and synoptic weather conditions during high pollution episodes. Journal of the Air and Waste Management Association, 52 (3), 287-296.

[10] Bernstein, J. A., Alexis, N., Barnes, C., Bernstein, I. L., Nel, A., Peden, D., Diaz-Sanchez, D., Tarlo, S.M., Williams, P. B. 2004. Health effects of air pollution. Journal of Allergy and Clinical Immunology, 114 (5), 1116-1123.

[11] Salam, M.A. 2006. Aerosol sampling methods in workplace and ambient environments. Journal of aerosol medicine, 19 (4), 434-455.
[12] Alves, C., Nunes, T., Silva, J., Duarte, M. 2013. Comfort parameters and particulate matter $\left(\mathrm{PM}_{10}\right.$ and $\left.\mathrm{PM}_{2.5}\right)$ in school classrooms and outdoor air. Aerosol Air Qual Res, 13, 1521-1535.

[13] Schwartz, J. 2004. Air pollution and children's health. Pediatrics, 113 (3), 1037-1043.

[14] Salvi, S. 2007. Health effects of ambient air pollution in children. Paediatric Respiratory Reviews, 8 (4), 275-280.

[15] Elbayoumi, M., Ramli, N. A., Yusof, N. F. F. M., Yahaya, A. S. B., Al Madhoun, W., Ul-Saufie, A. Z. 2014. Multivariate methods for indoor $\mathrm{PM}_{10}$ and $\mathrm{PM}_{2.5}$ modelling in naturally ventilated schools' buildings. Atmospheric Environment, 94, 11-21.

[16] Yang Razali, N. Y., Latif, M. T., Dominick, D., Mohamad, N., Sulaiman, F. R., Srithawirat, T. 2015. Concentration of particulate matter, $\mathrm{CO}$ and $\mathrm{CO} 2$ in selected schools in Malaysia. Building and Environment, 87, 108-116.

[17] Zhao, Z., Zhang, Z., Wang, Z., Ferm, M., Liang, Y., Norbäck, D. 2008. Asthmatic symptoms among pupils in relation to winter indoor and outdoor air pollution in schools in Taiyuan, China. Environmental health perspectives, 116 (1), 90-97.

[18] Burr, M. L., Anderson, H. R., Austin, J. B., Harkins, L. S., Kaur, B., Strachan, D. P., Warner, J. O. 1999. Respiratory symptoms and home environment in children: a national survey. Thorax, 54 (1), 27-32.

[19] Rawi, M. N. N. A., Jalaludin, J., Chua, P. C. 2015. Indoor air quality and respiratory health among Malay preschool children in Selangor. BioMed research international, http://dx.doi.org/10.1155/2015/248178 